\title{
Gérard Vigner, La grammaire en FLE
}

\section{Rachele Raus}

\section{OpenEdition}

\section{Journals}

Édition électronique

URL : http://journals.openedition.org/studifrancesi/36948

DOI : 10.4000/studifrancesi.36948

ISSN : 2427-5856

\section{Éditeur}

Rosenberg \& Sellier

\section{Édition imprimée}

Date de publication : 1 juillet 2005

Pagination : 218-219

ISSN : 0039-2944

\section{Référence électronique}

Rachele Raus, "Gérard Vigner, La grammaire en FLE », Studi Francesi [En ligne], 145 (XLIX | I) | 2005, mis en ligne le 30 novembre 2015, consulté le 19 avril 2021. URL : http://journals.openedition.org/ studifrancesi/36948; DOI : https://doi.org/10.4000/studifrancesi.36948

\section{Ce document a été généré automatiquement le 19 avril 2021}

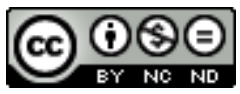

Studi Francesi è distribuita con Licenza Creative Commons Attribuzione - Non commerciale - Non opere derivate 4.0 Internazionale. 


\title{
Gérard Vigner, La grammaire en FLE
}

\author{
Rachele Raus
}

\section{RÉFÉRENCE}

GÉRARD VIGNER, La grammaire en FLE, Paris, Hachette, 2004, pp. 159.

1 Ce livre se veut une réflexion sur la grammaire en tant qu'outil indispensable d'apprentissage de la langue (FLE surtout, mais aussi FLM), considérant que tout en évitant des leçons de grammaire, les enseignants peuvent tout de même fournir aux étudiants une approche grammaticalisée de la langue. Partant d'une série de points d'interrogation, l'A. souligne la nécessité d'une approche grammaticalisée adaptée aux exigences concrètement observées en classe. Un deuxième chapitre développe justement l'idée de la grammaire en tant qu'«objet culturel» (p. 21), qui se différencie par rapport à l'apprenant envisagé, tout étudiant ayant un profil individuel conditionné aussi par le style d'apprentissage auquel l'école l'a habitué dans son pays. Dans le troisième chapitre, l'A. considère les deux domaines dont la grammaire doit s'occuper: d'un côté la langue dans sa dimension formelle (phrase / texte), de l'autre dans sa dimension d'usage (énoncé / discours). Il souligne en ce sens le décalage entre les pratiques d'enseignement, qui partent de l'approche énonciative, et les grammaires dans le commerce, qui ne fournissent que des descriptions de la langue. Même le métalangage grammatical apparaît traditionnel, bien que les dernières théories linguistiques considèrent l'énonciation et l'approche communicative comme centrales. Le quatrième chapitre, rappelant «qu'il ne saurait y avoir d'enseignement guidé d'une langue qui ne comprenne obligatoirement une dimension grammaticale» (p. 89), analyse les démarches inductives et déductives des grammaires et également l'hypothèse d'une "grammaire intériorisée», qui passe par l'acquisition d'une «intuition linguistique». Le cinquième chapitre montre le rôle de la grammaire dans tout apprentissage, en particulier par rapport aux compétences de lecture et d'écriture. Finalement, dans l'annexe, l'A. donne l'exemple de 5 grammaires dans le commerce, pour conclure que rechercher «la cohérence de la langue étrangère au-delà de la 
diversité de ses usages constitue l'objectif que doit se donner une approche grammaticalisée de la langue» (p. 157). 